Hydraulic Engineering Repository

Ein Service der Bundesanstalt für Wasserbau

Benamar, A.; Beaudoin, A.; Bennabi, A.; Wang, $H$. Experimental Study of Internal Erosion of Fine Grained Soils

Verfügbar unter / Available at:

https://hdl.handle.net/20.500.11970/100295

Vorgeschlagene Zitierweise / Suggested citation:

Benamar, A.; Beaudoin, A.; Bennabi, A.; Wang, H. (2010): Experimental Study of Internal Erosion of Fine Grained Soils. In: Burns, Susan E.; Bhatia, Shobha K.; Avila, Catherine M. C.; Hunt, Beatrice E. (Hg.): Proceedings 5th International Conference on Scour and Erosion (ICSE-5), November 7-10, 2010, San Francisco, USA. Reston, Va.: American Society of Civil Engineers. S. 368-377. 


\title{
Experimental Study of Internal Erosion of Fine Grained Soils
}

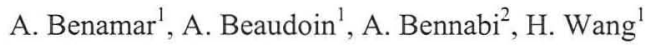 \\ ${ }^{1}$ LOMC FRE CNRS 3102, University of Le Havre BP 540 - 76058 - France; \\ email:benamar@univ-lehavre.fr; beaudoin@univ-lehavre.fr; huaqing.wang@univ- \\ lehavre.fr \\ ${ }^{2}$ GRG3, ESTP 28 Avenue Président Wilson 94234 Cachan - France ; email : \\ abennabiaradm.estp.fi
}

\begin{abstract}
Internal erosion has long been a major problem associated with earth structures. Laboratory experiments provide a potential insight into the processes involved. The design of dam embankments is usually based on hydraulic criteria. Some of the hydraulic criteria are based on sediment transport theory where the critical velocities are derived from the different approaches comparing the drag force of the particles and the hydraulic load. Many hydraulic criteria for suffusion are based on tests with consistent soil samples or on analytical descriptions of the particle and pore geometry derived from characteristic parameters. An experimental study of soil suffusion is performed on a laboratory column subjected to different flow conditions and soil parameters. The permeability variation along the soil column is controlled. The initiation and the kinetics of soil suffusion are investigated using a laboratory fine grained soil (mixed sand and clay) and a natural soil. Attempts are also made to assess the influence of the clay content and the type of fine particles. The results demonstrate that low hydraulic gradients can cause suffusion. The critical shear stresses for various soil tested differ slightly when the nature of grains and fines are varied. The hydraulic gradient affects the cumulative eroded mass upon a certain threshold value.
\end{abstract}

\section{INTRODUCTION}

Internal erosion takes place when water that seeps through the soil carries fines particles away from the embankment or foundation of dams. Internal erosion of soil particles is one of the most common causes for failure of the structures. This phenomenon is dangerous because it may not show external evidence that it is taking place. Natural clay in a dispersive state has been known as one of the fundamental factors that contribute to piping in earth dam and erosion of compacted soil of landfill clay liner. Internal erosion failures are often associated with penetrations of dams as outlet pipes buried in the embankment and concrete spillways that cross the embankment. Because of the embankment dams are constructed in zones of different materials, the deformations might also lead to cracks where internal erosion can be initiated. In the incidents of internal erosion, increased leakage was an evident problem. In several cases, sinkholes have formed in dams as a result of piping of well-graded core soils. These broadly-graded cores were glacial in origin with nearly linear gradations (Sherard, 1979). Filters have two basic functions, namely to prevent 
erosion and allow drainage of seepage water. The filtration of the silt-sized fraction is critical when soils are used for dam cores. In order to assess the stability of the broadly-graded soils, Sherard (1979) suggests splitting the gradation curve at the 1.0 $\mathrm{mm}$ particle size and analyzing it as two separate gradations. Vaughan and Soares (1982) suggest that permeability of the filter material should be the main measure for filter design. Kenney et al (1985) have carried out further investigations on pore size distribution of granular filters using either a theoretical or experimental approach. Sherard et al (1984) also carried out a series of experiments to evaluate the pore size of sand and gravel filters and concluded that pore sizes can be related to $\mathrm{D}_{15}$ size. Many studies regarding the design of filters have been done and currently Sherard and Dunnigan's (1989) results are widely used.

Before dispersion, eroded particles are significantly larger than the primary particles of the soil. This indicates that erosion occurs as aggregates of materials (Locke et al., 2000). The process of internal erosion is usually described by the initiation, continuation and progression phases. The identification of pipe development and the likely failure of the earth embankment lie in the understanding of the initiation mechanism of internal erosion. Suffusion is the process where the fine particles of the soil wash out or erode through the voids formed by coarser particles. As it takes place mainly due to the coarser particles, it can be prevented if the soil has well graded particle size distribution along with small voids. Lefebvre et al. (1986) investigated the influence of the natural structure of the undisturbed clay samples on the rate of erosion. They showed that the undisturbed structured clay provided much higher erosion resistance than the de-structured remoulded clay samples. Wan and Fell (2004a) used slot erosion and hole erosion tests to investigate the erosion resistance of the core material of fill dams. Both tests essentially adopted similar concepts, except that the slot erosion test possessed a longer flow channel. 14 different core materials were tested and an 'erosion rate index' was introduced to classify and grade the erosion resistance observed. A simplified approach was also proposed to assess the likelihood of internal erosion and piping in embankment dams. Wan and Fell (2004a, b) defined the variation of erosion rate assuming the erosion curves (i.e. erosion rate vs. shear stress) were linear with constant slopes. More recently, Wan and Fell (2004b) attempted multiple linear regressions to estimate the 'erosion rate index' based on the results of the hole erosion test and the slot erosion test. They proposed two equations for quantifying the rate of erosion, one for coarse-grained and the other for fine-grained soils. Sterpi (2003) performed laboratory tests and modelled the erosion and transport by combining the conservation of mass of moving particles with a suitable law of erosion, coupled with seepage equation. Gap grading in glacial deposits is a relatively common occurrence. These types of materials often have been used as construction materials for earthfill dams. Evidence between piping in dams and dykes and the presence of gap-graded materials within the structures and foundations was established (Fannin \& Moffat, 2006). The gap grading does not always occur within the finest fractions of the gradation curves and is often found in the middle fractions. Often, the missing materials are the medium to coarse sands. Recent experiences with piping incidences in dams seem to correlate with the occurrence of gap-grading in glacially derived soils. 
In this study we evaluate a criteria used for the soil stability against erosion. The term "suffusion" will be used to describe the mass movement of the fine fraction within the skeleton of potentially unstable soils. Suffusion tests were performed in the laboratory on reconstituted samples and embankment soil in order to assess the suitability of soil to erosion. Besides this experimental research, some attempts have been made to model the particle erosion and transport in a porous medium on the basis of numerical approach. A numerical model, based on advection-dispersion with a release term, is used to adjust the experimental results of the outlet concentration of removed fine particles.

\section{EXPERIMENTAL PROCEDURE}

The apparatus (figure 1) is typically a Plexiglas cylinder of $40 \mathrm{~mm}$ internal diameter and $120 \mathrm{~mm}$ length. The specimen rests on a lower mesh screen $(80 \mu \mathrm{m}$ opening size), supported on a perforated base plate and a large size opening mesh $(1.2 \mathrm{~mm})$ is used in the upper face. The specimen was reconstituted by mixing sand and clay in various proportions and deposited in the cylinder using a spoon and compacted (double compaction) at the fixed density of $1.53 \mathrm{~g} / \mathrm{cm}^{3}$. The fabric is believed best controlled than a natural compacted fill. Wet mixtures of graded sand and clay particles (kaolinite) in two proportions (3\% and $5 \%$ by weight), whose grading is presented on figure 2 , were used. The moulding water content at which the mixtures were prepared to achieve the fixed dry density was close to $6 \%$. The prorosity of reconstituted material was close to 0,42 and the initial hydraulic conductivity was estimated from seepage tests $\mathrm{k}=2.10^{-4} \mathrm{~m} / \mathrm{s}$ for $5 \%$ mixture and $\mathrm{k}=6.10^{-4} \mathrm{~m} / \mathrm{s}$ for $3 \%$ mixture. The upward seepage flow is induced by the assigned value of the hydraulic head, which depends on the difference in elevation between the upper reservoir and the overflow valve (Fig. 3). The height of the soil sample was maintained at $12 \mathrm{~cm}$ in all the experiments and the column is kept vertical. Suffusion tests were performed where water height was applied rapidly in some experiments (mixture 5\%) and gradually in others (mixture 3\%) to study the effect of time rate of pressure application on particle mobilization. Hence, after the soil was saturated under standing water, the water height was increased until and beyond erosion starts. Upward flow through the sample is head-controlled using a laboratory supply of distilled water at about $20^{\circ} \mathrm{C}$, which can be moved up in order to increase the water height. Differential pressure transducer mounted between the upstream and downstream of the soil sample establish the difference of water head, and hence the average hydraulic gradient along the specimen. Periodic measurement of volumetric discharge rate determines the corresponding hydraulic conductivity. The critical gradient obtained was 1,3 and 0,8 respectively for mixture $3 \%$ and $5 \%$. Outlet concentrations were determined by using a turbidity meter, whose readings were correlated previously to clay concentrations in water. Particles that wash from the specimen are collected in a tank. Upon completion of testing, one specimen was extracted from the cylinder for grain size analysis (Multisizer Malvern). In order to assess the suitability to suffusion of the side dam soils, an embankment sample soil coming from an earthfill dam was tested in the same erosion apparatus. Three processes are presumed to occur simultaneously during particle transport: 
Detachment of clay particles from the parent soil matrix; Transport of particles in pore water by convective-dispersive processes; Deposition of clay particles which may be trapped in some pores owing to local changes in pore flow velocities or variations in pore geometry. The removal of particles from the soil matrix into pore water suspension causes an increase in pore space, which in turn increases the permeability of the medium. If the soil sample is subjected to a constant external pressure gradient, then the flow velocity (both Darcian and seepage) increases, which in turn causes more particles to be removed. One may be led to believe that this process would continue indefinitely and wash out the sample entirely. However, the soil matrix is held together rigidly and the applied stresses can not remove more than a fraction of available fine particles.

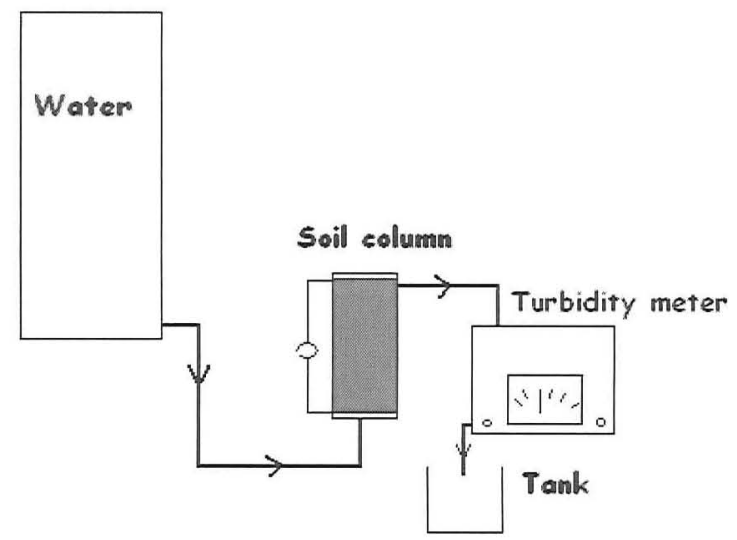

Figure 1. Drawing schema of the experimental set up

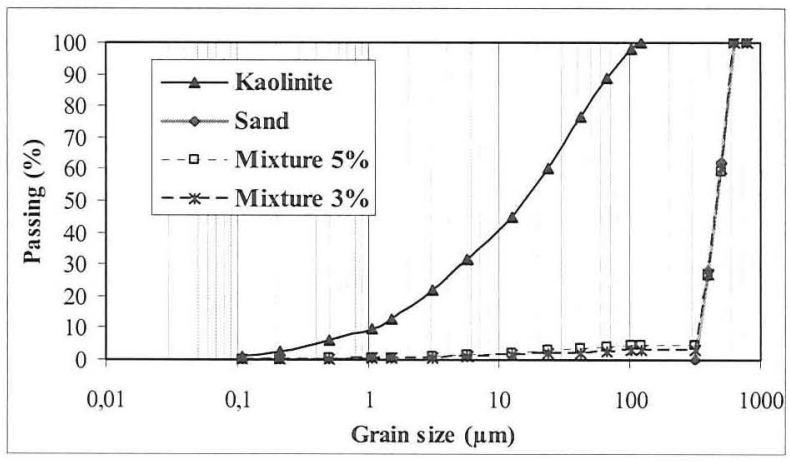

Figure 2. Gradation curves of materials and mixture 


\section{RESULTS AND DISCUSSION}

\section{Suffusion of laboratory mixed soil}

In order to better understand the internal behaviour of gap-graded soils, tests were performed with different mixtures of sand and clay. Suffusion process occurs if fine particles are removed from the soil matrix and transported outlet the sample. The main objective of the test was to determine the steady-state gradients required to initiate fines migration in the soil. The erosion characteristics are typically described the critical shear stress, which represents the minimum shear stress when erosion starts. It is known (Wan and Fell, 2004) that coarse-grained, noncohesive soils erode more rapidly and have lower critical shear stresses than fine-grained soils. Knowledge of the erosion characteristics of the soil in the core of an embankment dam must help in the assessment of the likelihood of dam failure due to piping erosion.

The results of suffusion tests are analyzed using the outlet curves of measured concentration. Figure 3 below shows the concentration-time curves obtained for two mixtures $(5 \%$ and $3 \%)$. The soil containing $3 \%$ of kaolinite presents earlier significant suffusion and the curve reaches rapidly a peak concentration before decreasing and then increasing to a second peak before falling to zero. The flow rate being more important (six times) in mixture $3 \%$, the drag forces are able to mobilize in a second step more particles which remain attached in the mixture $5 \%$. The mixture with $5 \%$ kaolinite seems to let the particles to be removed from the soil less rapidly but with more consistent duration of concentration effluent. The maximum concentration reached is close to that of $3 \%$ mixture. More residual concentration is observed over the time, showing a continuous suffusion even with a weak magnitude. This result indicates the effect of particle content in the soil on the susceptibility to suffusion and the cumulated particle removal. The $5 \%$ kaolinite curve shows an earlier slight suffusion due to an easy removal of particles in the vicinity of the outlet.

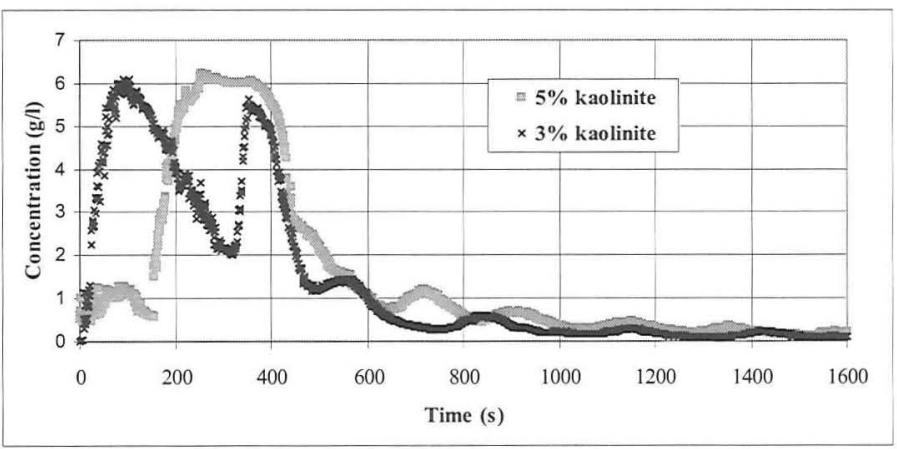

Figure 3. Concentration-time curves of two tested soil mixtures 
The widely used process for determining internal instability of a soil against suffusion is that described by Kenney and Lau (1985). This method assesses the removal of the free fines under the velocity of flow. The free fines are considered here to be the kaolinite particles. Kenney and Lau suggest a method for predicting the material response based on the analysis of the "shape curve" of the material grading. This curve is drawn by plotting, for each value of grain size $D$, the percentage of mass having grain sizes between $\mathrm{D}$ and $4 \mathrm{D}$ ( $\mathrm{H}$ value) versus the percentage of mass having a grain size smaller than D ( $F$ value). A shape curve lying below the suggested boundary line $(\mathrm{H}=\mathrm{F})$ indicates unstable grading. The Kenney-Lau plot of the soil with $5 \%$ of fines is shown on Figure 4. The plot indicates that the soil of mixture $5 \%$ is well below the $\mathrm{H}=\mathrm{F}$ line when $\mathrm{F}$ is below 5 percent (fines content), indicating that this material should be internally unstable against movement of fines and vulnerable to suffusion. This material has a large gap in grain size curve (Fig. 2), yielding a $\mathrm{D}_{15} / \mathrm{d}_{85}=6$ that is deemed unstable according to Sherard criteria.

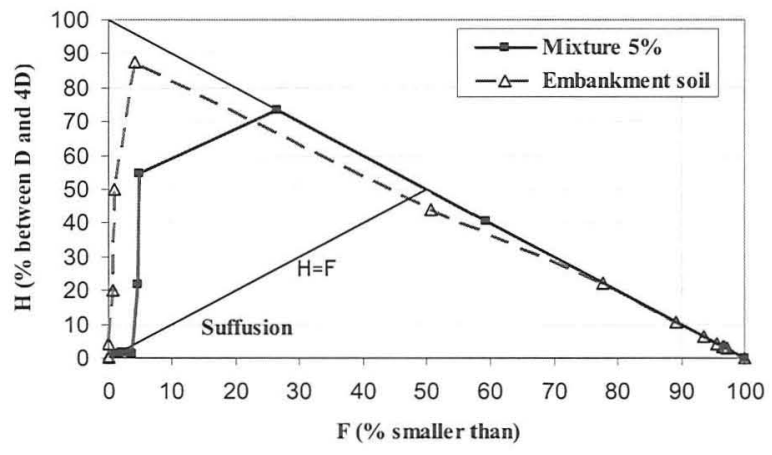

Figure 4. Plot of Kenney-Lau criteria for internal stability

\section{Suffusion of embankment soil}

In order to test a natural soil against suffusion, a sample embankment soil (a silty sand) is subjected to water flow. The hydraulic gradient was increased until the erosion was initiated (when the gradient was close to 7.5), and then the water head was maintained at steady-state and outlet concentration measured (using turbidity sensor device). Outlet flow samples are collected in order to analyse the size particles distribution using a laser multisizer (Malvern). Figure 5 shows the initial complete gradation of the soil and the gradations of the fines $(<80 \mu \mathrm{m})$ before and after suffusion. The gradation curves of the fines show that the medium fraction of fines (sizes between 0.5 and $50 \mu \mathrm{m}$ ) was mainly removed from the soil.

The Kenney-Lau plot of the embankment soil is also presented on Figure 4. This material provide a curve which is above the line $\mathrm{H}=\mathrm{F}$, indicating that this material is internally stable against suffusion. This result is corroborated by the suffusion test where the removal of particles was started at a relatively high hydraulic gradient $(\mathrm{i}=$ 7,5). However, the plot indicates also that the soil is well above the $\mathrm{H}=\mathrm{F}$ line when $\mathrm{F}$ is below 50 percent. This indicates that this material should be internally sometimes unstable against suffusion. 


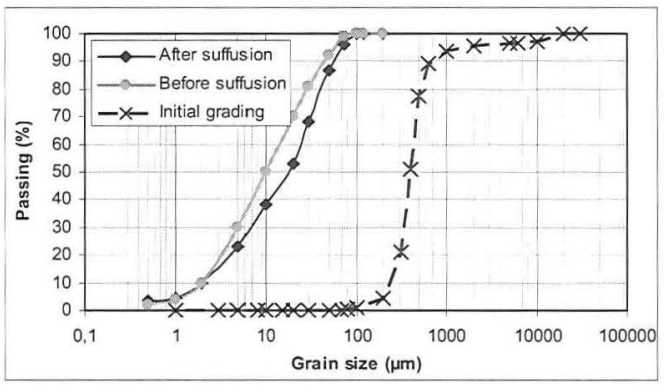

Figure 5. Gradation curves of embankment soil

\section{MODELLING OF EROSION}

The transport of suspended particles in porous media under saturated flow conditions is commonly described using the convection dispersion equation below:

$\frac{\partial\left(w_{c}(t, x) C(t, x)\right)}{\partial t}=\frac{\partial}{\partial x}\left(D_{L}(t, x) \frac{\partial\left(w_{c}(t, x) C(t, x)\right)}{\partial x}\right)-\frac{\partial\left(U(t, x) w_{c}(t, x) C(t, x)\right)}{\partial x}+\frac{\partial\left(\rho_{p} w_{c}(t, x)\right)}{\partial t}$

where $\mathrm{w}_{\mathrm{c}}$ refers to the effective porosity, $\mathrm{C}$ the suspended particles concentration, $D_{L}=\alpha_{L} U$ the hydrodynamic dispersion, $\alpha_{L}$ the longitudinal dispersivity, $U$ the pore flow velocity and $\rho_{\mathrm{p}}$ the bulk density of suspended particles. In order to take into account the processes of particle deposition and release, a kinetic of the first order is introduced:

$$
\frac{\partial\left(\rho_{\mathrm{p}} \mathrm{w}_{\mathrm{c}}(\mathrm{t}, \mathrm{x})\right)}{\partial \mathrm{t}}=\rho_{\mathrm{p}} \mathrm{K}_{\mathrm{rel}}\left(\mathrm{w}_{\mathrm{o}}-\mathrm{w}_{\mathrm{c}}(\mathrm{t}, \mathrm{x})\right)-\mathrm{K}_{\mathrm{dep}} \mathrm{w}_{\mathrm{c}}(\mathrm{t}, \mathrm{x}) \mathrm{C}(\mathrm{t}, \mathrm{x})
$$

where $\mathrm{w}_{\mathrm{o}}$ is the total porosity, $\mathrm{K}_{\mathrm{rel}}$ and $\mathrm{K}_{\text {dep }}$ are the coefficients of release and deposition kinetics. The initial and boundary conditions are given by:

$$
C(t=0, x)=0 \text { and } \quad \frac{\partial C}{\partial x}(t, x)=0
$$

By introducing the new variables $\mathrm{S}=\partial\left(\rho_{\mathrm{p}} \mathrm{w}_{\mathrm{c}}\right) / \partial \mathrm{t}$ and $\mathrm{C}_{\mathrm{T}}=\mathrm{w}_{\mathrm{c}} \mathrm{C}$, Eq. 1 can be written as:

$$
\frac{\partial \mathrm{C}_{\mathrm{T}}(\mathrm{t}, \mathrm{x})}{\partial \mathrm{t}}=\frac{\partial}{\partial \mathrm{x}}\left(\mathrm{D}_{\mathrm{L}}(\mathrm{t}, \mathrm{x}) \frac{\partial \mathrm{C}_{\mathrm{T}}(\mathrm{t}, \mathrm{x})}{\partial \mathrm{x}}\right)-\frac{\partial\left(\mathrm{U}(\mathrm{t}, \mathrm{x}) \mathrm{C}_{\mathrm{T}}(\mathrm{t}, \mathrm{x})\right)}{\partial \mathrm{x}}+\mathrm{S}(\mathrm{t}, \mathrm{x})
$$


The particle methods are well adapted to solve the problems dominated by the advection process. By using the dispersion velocity method, the advection dispersion equation (Eq. 4) is rewritten on the form of an advection equation (Lions et al., 2001):

$$
\frac{\partial \mathrm{C}_{\mathrm{T}}(\mathrm{t}, \mathrm{x})}{\partial \mathrm{t}}+\frac{\partial\left(\left(\mathrm{U}(\mathrm{t}, \mathrm{x})+\mathrm{U}_{\mathrm{d}}(\mathrm{t}, \mathrm{x})\right) \cdot \mathrm{C}_{\mathrm{T}}(\mathrm{t}, \mathrm{x})\right)}{\partial \mathrm{x}}=\mathrm{S}(\mathrm{t}, \mathrm{x})
$$

where $\mathrm{U}_{\mathrm{d}}$ is the dispersion velocity, obtained by identifying the previous equation with the equation (Eq. 1):

$$
\mathrm{U}_{\mathrm{d}}(\mathrm{t}, \mathrm{x})=-\mathrm{D}_{\mathrm{L}}(\mathrm{t}, \mathrm{x}) \frac{\partial\left(\mathrm{C}_{\mathrm{T}}(\mathrm{t}, \mathrm{x})\right) / \partial \mathrm{x}}{\mathrm{C}_{\mathrm{T}}(\mathrm{t}, \mathrm{x})}
$$

To solve the equation (5), it has to be written in a Lagrangian framework yielding the discrete form:

$$
\frac{\mathrm{dx}_{\mathrm{i}}}{\mathrm{dt}}=\mathrm{U}\left(\mathrm{t}, \mathrm{x}_{\mathrm{i}}\right)+\mathrm{U}_{\mathrm{d}}\left(\mathrm{t}, \mathrm{x}_{\mathrm{i}}\right) \text { and } \frac{\mathrm{d} \Omega \mathrm{i}}{\mathrm{dt}}=\int_{\mathrm{Pi}} \mathrm{S}(\mathrm{t}) \mathrm{ds}
$$

As usual in the particle methods, the term $\mathrm{C}_{\mathrm{T}}$ is discretized in a set of moving particles $P_{i}$ defined by its location $x_{i}$ and its weight $\Omega_{i}$. The first equation (7) is an evaluation of characteristic lines, performed by using the explicit Euler scheme and the second equation (7) describes the temporal evolution of weight of particles, estimated by means of a simple Euler scheme. The particle methods offer the advantage to verify automatically the initial condition (Eq. 3) and the boundary conditions (Eq. 3) are satisfied by using the ghost particle method (Cleary et al., 1999).

In suffusion, the processes of particle detachment, transport and deposition are assumed to occur simultaneously. In order to uncouple detachment and transport from deposition, the model is modified by making the deposition kinetics null in Eq. 2 . In order to reduce the number of parameters to be adjusted, the present numerical model is arranged to model only the suffusion (release of particles). Dedicated test ("clean" suffusion) was then carried out using a thin soil sample (mixture of sand 0,8-1 mm and $2 \%$ silt) placed at the extremity of the column before a sand filter, making the flow rate homogeneous along the column. The suffusion tests with rapid pressure application (gradient close to 7) were performed on the soil with primary porosity close to $42 \%$. The performance of the model by comparison with experimental results is discussed. The concentration-time curves and the results of cumulative mass removal are presented for model validation. The concentration-time curves indicate that the amount of removed particles is influenced by fines content significantly. Fig. 6(a) shows experimental and numerical results of concentrationtime curve and Fig. 6(b) shows the cumulative amount of particle removed as a function of time. A good agreement is obtained, even if the numerical peak concentration being slightly greater than the measured one. Both the experimental and numerical curves (fig. 6a) show the initial steep rise in concentration resulting from the imposed hydraulic gradient rate and the abrupt drop in concentration once the pressure is maintained steady. Consequently, soil detachability is very high. The 
numerical and experimental curves of the cumulative particles removed from the soil sample (fig. 6b) show a fast initial removal which slows down once the pressure remains constant. The fast rise and fall of the concentration are well captured by the numerical curve. The results indicate that the rate of particle removal reaches a constant asymptotic value. The numerical cumulative particle removal overestimates slightly the experimental concentration. These results indicate that the model proposed shows promise for future development and application in particle transport at the laboratory scale.

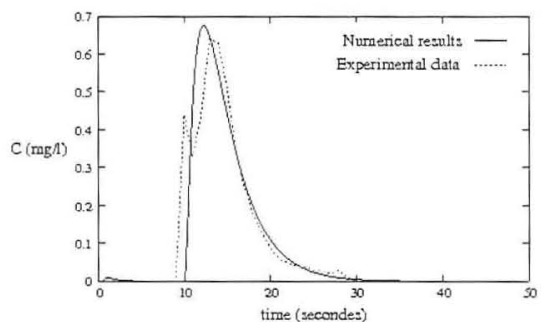

(a)

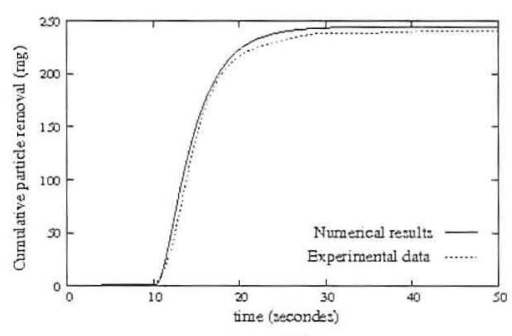

(b)

Figure 6. Numerical and experimental concentration-time curves (a) and cumulative particle removal (b) for coarser soil sample with initially $2 \%$ silt subjected to rapid pressure application.

\section{SUMMARY AND CONCLUSIONS}

This paper dealt with the results of an experimental investigation of the suffusion of gap-graded soils and the development of a numerical model simulating particle removal in laboratory columns subjected to external gradients. This study shows that gap-graded materials often suffer internal erosion at relatively low hydraulic gradient. The process of suffusion can produce high gradient within internally unstable materials. The potential for instability is governed by the shape of the grain size distribution curve, which may be quantified using the split gradation method according to Sherard (1979) and evaluated with the ratio $\mathrm{D}_{15} / \mathrm{d}_{85}$. The mixed soil with this ratio close to 6 exhibited internal instability at relatively low gradient. The analysis of outlet concentration-time curves for soil mixtures with different clay content allows concluding about the influence of fines content on the erosion rate and the initiation of the process. The sample subjected to a rapid pressure application exhibited the initial steep rise in concentration and the abrupt drop, while the test performed with gradual pressure application shows a steady-state concentration at outlet before decreasing progressively.

Comparison of model and experimental results indicated a quite good agreement. These results indicate that the model proposed shows promise for future development and application in particle transport at the laboratory scale. However, this model is applicable to homogeneous soils at the laboratory column scale. 


\section{ACKNOWLEDGMENTS}

This study is part of a French national research program ERINOH (ERosion Interne des Ouvrages Hydrauliques).

\section{REFERENCES}

Becker, D.E., Crooks, J.H.A., Been, K., and Jefferies, M.G. (1987). "Work as a criterion for determining in-situ and yield stresses in clays." Canadian Geotech. J. 24 (4): 549-564.

Cleary, P.W. and Monaghan, J.J. (1999). "Conduction modeling using smoothed particle hydrodynamics." J. Computational Physics 148: 227-264.

Cottet, G.H. and Koumoutsakos, P. (2000). "Vortex Methods Theory and Practice". Cambridge University Press.

Fannin, R.J., Moffat, R., (2006). "Observations on internal stability of cohesionless soils", Geotechnique 56 (7), 497-500.

Fell, R., Wan, C. F., Cyganiewicz, J. \& Foster, M., (2003). "Time for development of internal erosion and piping in embankment dams." J. Geotech. Geoenviron. Engrg. 129(4), 307-314.

Kenney, T. C., Chahal, R., Chiu, E., Ofoegbu, G. I., Omange, G. N. \& Ume, C. A., (1985). "Controlling constriction sizes of granular filters." Canadian Geotech. J. 22(1), 32-43.

Lefebvre, G., Rohan K., Douville S., (1985). « Erosivity of natural intact structured clay : Evaluation.» Canadian Geotech. J. 22, 508-517.

Lions, P.L and Mas-Gallic, S. ,(2001). "Une méthode particulaire déterministe pour des equations diffusives non linéaires." C.R. Acad. Sci. Paris 332 (série 1): 369-276.

Locke, M., Indraratna, B., Cummins, Philips, and Adikari, G., (2000). "Embankment Dam Rehabilitation", ANCOLD 2000 Conference on Dams.

Sherard, J. L., (1979). "Sinkholes in dams of coarse, broadly graded soils." 13th Int. Congress on Large Dams, New Delhi, Q49, R2, 25-35. International Commission on Large Dams, Paris.

Sherard, J. L. \& Dunnigan, L. P., (1989). "Critical filters for impervious soils.” J. Geotech. Engrg. 115(7), 927-947.

Sherard, J. L., Dunnigan, L. P. \& Talbot, J. R., (1984). "Basic properties of sand and gravel filters." J. Geotech. Engrg. 110(6), 684-700.

Sterpi, D., (2003). "Effects of the Erosion and Transport of Fine Particles due to Seepage flow", Int. J. Geomechanics, 3 (1), 111-122.

Vaughan, P.R., and Soares, H.F. (1982). "Design of filters for clay cores of dams." $J$. Geotech. Engrg. 108: 17-33.

Wan, C.F. and Fell, R. (2004a). "Investigation of rate of erosion of soils in embankment dams." J. Geotech. and Geoenvir. Engrg. 30 (4): 373-380.

Wan, C.F. and Fell, R. (2004b). "Laboratory tests on the rate of piping erosion of soils in embankments dams." Geotech. Testing J. 27 (3). 